\title{
A Study on Investment Behaviour and Attitude of Women Investors of Bangalore, Karnataka
}

\author{
R. Ganapathi ${ }^{1}$ and Varsha Madhavan ${ }^{2}$ \\ ${ }^{1}$ Assistant Professor, Directorate of Distance Education, ${ }^{2}$ Research Scholar \\ ${ }^{1 \& 2}$ Alagappa University, Karaikudi, Tamil Nadu, India \\ E-mail: varshamadhavan28@gmail.com
}

\begin{abstract}
Investment is one of the pre - eminent concern of every single individual investor as the small savings of today are to meet the future expenses of tomorrow. Considering the survey over 120 respondents from Bangalore City among women, this paper attempts to study the behaviour and attitude of investment based on the socio-economic profile, awareness and preferences and financial literacy over various investment avenues that are available in India. The study was conducted during the pandemic period from March to July as many of the women investors resulted in unemployment that affected their income, earnings and savings. Fort the study the data was collected using structured questionnaires. The result showed that most of the women investors belongs to a less age group as they are into a working class and to which most of them are comfortable in traditional mode of investment such as secured deposits. The study also revealed investment in stock market is bit sceptical as it involves high risk and uncertainty. The result also says the psychological behaviour of Indian women as they are fond of bullion and investing in bullion metals is quite attractive and low risk. From the study point, it will help to explore and expand knowledge and identify the best avenue to invest and create savings for the better future in the field of personal finance and pandemic recession.
\end{abstract}

Keywords: Investment, Women Investors Savings, Financial Market

\section{INTRODUCTION}

Investment is the employment of funds on assets with the aim of earning income or capital appreciation Investment has two attributes namely time and risk. Present consumption is sacrificed to get a return in the future. The sacrifice that has to be borne is certain but the return in the future may be uncertain. This attribute of investment indicates the risk factor. The risk is undertaken with a view to reap some return from the investment. For a layman, investment means some monetary commitment. A person's commitment to buy a flat or a house for his personal use may be an investment from his point of view. This cannot be considered as an actual investment as it involves sacrifice but does not yield any financial return.

Women investors' behaviour - An Introduction Investment behaviour are defined as how the investors judge, predict, analyse and review the procedures for decision-making, which includes investment psychology, information gathering, defining and understanding, research and analysis. The whole process is "Investment Behaviour"
(Slovic, 1972; Alfredo and Vicente, 2010). The foreign and Indian researchers surveyed on women investors' behaviour unanimously agree that women are not active investors, they are less likely to take above-average or substantial risk when choosing investments and their investment decisions are cantered on family circumstances. Regarding women's likes and dislikes towards investment, the researchers are of the view that women do not describe themselves as being confident or knowledgeable about investing. They do not have diversified portfolios. They do not review and compare their investment performance with market benchmarks on a regular basis. They do not have control of their investments or have a consistent investment strategy. They are not satisfied with their current investment allocation. They do not invest regularly. They are less likely to have started investing early in life. Women are more willing to wait if an investment did not produce the expected return. They consult with a financial advisor when their investment did not perform as expected. This behaviour well explains their cautious approach towards investment. Women's involvement in saving and investing is due to a specific life event (the birth of a child, a divorce, retirement, a death or sudden financial gain). This involvement is often sudden. In terms of learning, women are more likely to know all of the details in fine print when learning something new about investing.

Online investing and Women According to Ms Madeline Thomas (article on 'Online Investing and Women') private investing, day-trading and playing the stock market has always been a very male affair. Yet, over the past decade more and more women have joined in. Ten years ago, just $17 \%$ of the investors who used the online broker Self trade were women. In 2010, the user base has risen to $34 \%$. This trend is not restricted to the one website. As per the report of Tokopedia, a site specializing in broker research and stock market analysis, between $30 \%$ and $40 \%$ of its user base is female. There are increasing numbers of smart, savvy women out there who are taking up the challenge of making their own investment decisions. The increasing availability of information and share services online has helped fuel this trends.

Investment is the commitment of money that has been saved by the deferring the consumption and purchasing power of an individual investors. It is often believed that investors are 
the back of a country's capital market. A developing country like India the growth of an economy is highly appreciated and depended on the individual investments and savings which would flow into the growing corporate enterprises. Each individual investor is bond to differ in their investment patters and it is highly characterized by the virtue of demographic determinants such as age education gender financial knowledge social status, commitments, financial credibility, age of retirement etc. Each individual investor selects the investment based on the personal financial goals which is considered for the certain duration of time period. (Rao Maddala Papa). Investment is the commitment of money that has been saved by the deferring the consumption and purchasing power of individual investors. It is often believed that investors are the back of a country's capital market. A developing country like India the growth of an economy is highly appreciated and depended on the individual investments and savings which would flow into the growing corporate enterprises. Each individual investor is bond to differ in their investment patters and it is highly characterized by the virtue of demographic determinants such as age education gender financial knowledge social status, commitments, financial credibility, age of retirement.

\section{REVIEW OF LITERATURE}

Lubna Ansari and Ms Sana Moid According to the study it can be inferred that majority of investors invest for growth and additional income and the major factor that guides their investment decision is risk factor which means that investors mostly are risk young investors generally take trading decisions based on their self-perceived competence but sometimes considering the efforts made in by the portfolio managers advisors too. Sometimes the investment objectives also differ on the financial stability and additional income and so on.

Bhushan \& Medury (2013) founded that woman takes less risk and majorly gender differences occur in investment preferences for health insurance, fixed deposits and market investments among employees and so on.

Sellappan et al., (2013) According to the study it is estimated that married women are more interested in making investment than the unmarried. As well as the younger women invest in shares, mutual funds, insurance and fixed deposits than the older women. The middle age women are interested to invest in real estate.

Dev Prasad, M. R. Shollapur (2014) It is highlighted that the Indian Women Investors as Emotional Decision Makers, this study expects to contribute to the literature by focusing on the investment behaviour of Indian women investors in what is predominantly still a male dominated market, whether the human motions of greed, fear, love, and disbelief influence the decision-making process of women investors considering investment opportunities in the Indian stock market.
Juwairiya, P. P. (2014) had an analysis on financial literacy and investment pattern of working women in Kerala with the objective to find out the financial literacy among the working women's in Kerala and their investment behaviour and it was conducted in descriptive style by using both primary and secondary data. The study found that investment behaviours of working women are conservative in nature.

\section{OBJECTIVES OF THE STUDY}

1. To study the socio - economic profile and investment activities of women investors in Bangalore.

2. To understand the women investors awareness, preferences \& information towards the mutual funds \& share market.

3. To analyse the investment decision process of Women investors.

\section{RESEARCH METHODOLOGY}

The study is based on primary data. Quantitative research method is adopted to collect data and conduct the investigation, and further tabulation is also made for the study. A well-mannered questionnaire was prepared to cater the information for the study.

A. Sample Size: Out of 200 target respondents only 120 potential women investors responded towards the questionnaires from Bangalore. The survey was done during the pandemic lockdown period starting from March to July.

B. Statistics Used: Percentile analysis. Microsoft excel is also used for the study for tabulation and analysis of the data.

C. Scope of the Study: This study is focusing on the investment behaviours and attitude of women towards investment in Bangalore City which would enable to explore, identify and prefer more investment options available in current market considering the current pandemic situation and also being an active member in the current market where one has to make a decision on savings for the better world and standard of living.

\section{Data Collection}

For the study both primary and secondary data were used. Primary data by structured questionnaires and personal interviews with women investors, the respondents consist of Salaried women, Entrepreneurs and Self- Employed women who is involved in minor and major business activities in Bangalore, who possess good knowledge about financial market and investments. Secondary data was collected through research articles, company websites, journals and text books to cater the information on financial investment avenues. Out of 200 respondents 120 respondents were received. The below mentioned table consist of demographic information. 


\section{E. Data Analysis and Interpretation}

TABLE I INVESTORS'INVESTMENT ACTIVITIES

\begin{tabular}{|l|c|c|}
\hline \multicolumn{1}{|c|}{$\begin{array}{c}\text { Factors Motivated for } \\
\text { Investment }\end{array}$} & Frequency & Percentage \\
\hline Earning Income & 40 & 31 \\
\hline Education \& Marriage & 21 & 19 \\
\hline Emergency & 29 & 23 \\
\hline Expand Business & 5 & 4 \\
\hline $\begin{array}{l}\text { Provision for Old Age \& } \\
\text { Contingencies }\end{array}$ & 10 & 9 \\
\hline Social Consideration & 5 & 5 \\
\hline Tax Benefits & 10 & 9 \\
\hline Total & 120 & 100 \\
\hline
\end{tabular}

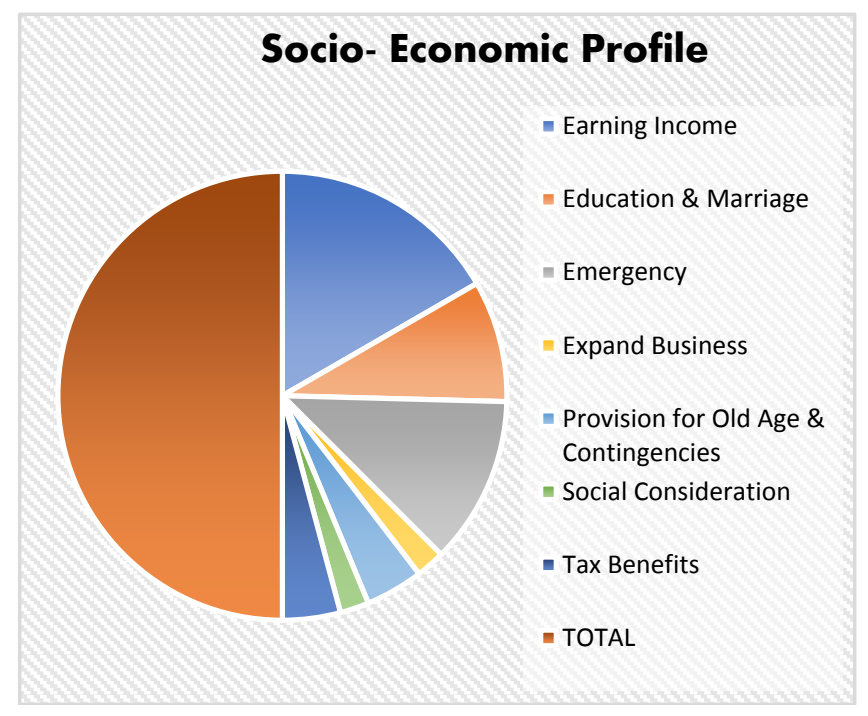

Fig. 1 Socio Economic Profile on Investment

TABLE II INCOME ISINVESTED

\begin{tabular}{|l|c|c|}
\hline $\begin{array}{c}\text { Percentage of } \\
\text { Investment }\end{array}$ & Frequency & Percentage \\
\hline $10 \%$ to $20 \%$ & 50 & 41 \\
\hline $20 \%$ to $30 \%$ & 30 & 25 \\
\hline Less than $10 \%$ & 39 & 33 \\
\hline More than $30 \%$ & 1 & 1 \\
\hline Total & 120 & 100 \\
\hline \multicolumn{3}{|c|}{ Source: Primary Data }
\end{tabular}

Interpretation: The above tabular representation of II shows that $41 \%$ of the respondent decides to have $10 \%$ to $20 \%$ where as $20 \%$ to $30 \%$ only $25 \%$ of the respondent have their income invested whereas less than $10 \%$ only $33 \%$ of the respondent whereas only $1 \%$ of the investor has investment of income invested more than $30 \%$ where most of the women have invested $10 \%$ to $20 \%$ of their income making them conservative investors. Then few of them have invested $10 \%$ of their income which is not a big percentage and few of them have invested in $20 \%$ to $30 \%$ of their income as many women don't have a thorough knowledge of all the investment avenues and the least percentage of women have invested more than $30 \%$ as they don't want to take risks.

TABLE III SHOWING THESE ARE INCOME OBJECTIVES OF THE INVESTORS

\begin{tabular}{|l|c|c|}
\hline \multicolumn{1}{|c|}{ Investment Objective } & Frequency & Percentage \\
\hline Capital Appreciation & 4 & 3.3 \\
\hline Income Generation & 35 & 29.2 \\
\hline Liquidity & 16 & 13.3 \\
\hline Long-Term Growth & 40 & 33.3 \\
\hline Short-Term Growth & 20 & 16.7 \\
\hline Wealth Creation & 5 & 4.2 \\
\hline Total & 120 & 100 \\
\hline
\end{tabular}

Interpretation: The above table III shows out of 120 respondent 40 respondent has their investment objective of long-term growth whereas 35 respondent belongs for the income generation and it shows that 16 and 20 of the respondents belongs to short term growth and also on the basis of liquidity and the least is for the capital appreciation and the wealth creation as the respondents are 4 and 2.

The above graphical representation of III depicts that most of the women have financial goals of investment behaviour which has long term growth at the highest $33.3 \%$ along with generation of income $29.2 \%$. Whereas the investors have less focus on capital appreciation 3.3\% and wealth creation $4.2 \%$. The respondent with $13.3 \%$ they focus on the liquidity of the investment whereas the investors with minimum requirement always suggest to have the investment objective in short term growth $16.7 \%$ as the income has a great impact on their investment objective.

Interpretation: The below table IV represent that preference of investment avenues of the working women. It clearly states that clearly shows that there is an equal amount of preference given to these cured deposit schemes and post office schemes as it is common kind of investment avenues which will be familiar for the working women as it is convenient and easy.

Same way it's a tendency of all the women to invest in Gold and LIC which they assure in returns whenever it is possible. As the above graph shows that women are least interested in in investing in art, antiques Equity shares Bonds etc. 
TABLE IV SHOWING THE PREFERRENCE OF INVESTMENT AVENUES

\begin{tabular}{|c|c|c|c|c|c|c|c|}
\hline \multirow{2}{*}{ Investment Avenue } & \multicolumn{6}{|c|}{ Frequency } & \multirow[b]{2}{*}{$\%$} \\
\hline & Highly Likely & Likely & Neutral & Unlikely & Highly Unlikely & Grand Total & \\
\hline LIC policy life insurance & 60 & 53 & 4 & 2 & 1 & 120 & $94 \%$ \\
\hline Real Estate & 1 & 1 & 8 & 90 & 20 & 120 & $8.33 \%$ \\
\hline $\begin{array}{l}\text { Secured Deposits (Fixed } \\
\text { Deposits, other deposits etc.) }\end{array}$ & 70 & 47 & 2 & 0 & 1 & 120 & $99 \%$ \\
\hline Bullion (Gold, Silver metals) & 30 & 60 & 25 & 4 & 1 & 120 & $95 \%$ \\
\hline Mutual Funds /ULIP/ELISS & 9 & 55 & 50 & 5 & 1 & 120 & $95 \%$ \\
\hline Art, Antiques Pieces & 1 & 0 & 5 & 70 & 44 & 120 & $5 \%$ \\
\hline $\begin{array}{l}\text { Equity Shares of a } \\
\text { companies }\end{array}$ & 2 & 8 & 10 & 40 & 60 & 120 & $16 \%$ \\
\hline Postal Savings Scheme & 70 & 40 & 4 & 5 & 1 & 120 & $95 \%$ \\
\hline Bonds/ Debentures & 3 & 5 & 40 & 20 & 52 & 120 & $40 \%$ \\
\hline Total & 246 & 269 & 148 & 236 & 181 & 1080 & \\
\hline
\end{tabular}

TABLE V TIME PERIOD AND INFORMATION TO INVEST

\begin{tabular}{|l|c|c|}
\hline $\begin{array}{c}\text { The Time Period / } \\
\text { Duration of Investment }\end{array}$ & Frequency & Percentage \\
\hline Long term (>5) & 37 & 31 \\
\hline Medium term (1-5) & 70 & 58 \\
\hline Short term (0-1) & 13 & 11 \\
\hline Total & 120 & 100 \\
\hline \multicolumn{3}{|c|}{ Source: Primary Data }
\end{tabular}

Interpretation: The above table $\mathrm{V}$ represent that time period of the investors as the majority of the women prefer investing in medium term investments. Very few of the women use short term investments $11 \%$ as women generally invest in funds which generate incomes in shortterm. The table represents that $58 \%$ of the working women prefer to invest in medium term as the return, they may except lasting neither long nor short. As the survey shows that there is a $95 \%$ preference in mutual fund where it is a best avenue that 1 to 5 years of investment decision for the long-term performance. $31 \%$ of the working women prefer to invest for the period more than 5 years as they expect high returns. Whereas $11 \%$ of the respondents invest for a shortduration.

TABLE VI SHOWING THE INVESTMENTDECISION PROCESS

\begin{tabular}{|l|c|c|}
\hline \multicolumn{1}{|c|}{ Preferences of Investment } & Frequency & Percentage \\
\hline $\begin{array}{l}\text { Fixed income securities (FD, } \\
\text { RD, Bonds) }\end{array}$ & 50 & 41 \\
\hline $\begin{array}{l}\text { High risk securities (Hedge, } \\
\text { swap and future) }\end{array}$ & 1 & 16 \\
\hline $\begin{array}{l}\text { Low risk securities (Mutual } \\
\text { funds \& Gold) }\end{array}$ & 50 & 42 \\
\hline $\begin{array}{l}\text { Mid risk securities (Share and } \\
\text { commodity market) }\end{array}$ & 19 & 01 \\
\hline Total & 120 & 100 \\
\hline
\end{tabular}

Interpretation: The above table VI represent that most of the working women prefer to invest in Low-risk securities and fixed income securities as $42 \%$. Because these are the familiar investment in every women life as well as it is directly impacted with their age and income. Whereas Investments are also risky most times when compared to savings therefore we can see that out of 120 respondent 1 women prefer to invest in high-risk securities. As we all as we can see that $16 \%$ of them prefer to invest in shares and commoditymarket.

The table represent that $41 \%$ of the working women prefer to invest in fixed income securities as there is high diversification from the stock market, capital preservation and which also help in the income generation as these are the steady source of income. Whereas $42 \%$ of the respondent prefers to have Low risk securities as it has high yield of saving accounts such as Gold and Mutual Fund these kinds of investment provide interest rate on the basis of capital.16\% of the respondents prefer to invest in highrisk securities such as Hedge, Swap and Future as we can see that the survey most of the women does not prefer these kinds of investment. $1 \%$ of the respondents prefer to invest in Mid risk securities as it has high risk but with good returns.

TABLE VII SHOWING THE INVESTORS DECISION MAKING ON INVESTMENT

\begin{tabular}{|l|c|c|}
\hline Decision Maker & Frequency & Percentage \\
\hline Family & 1 & 1 \\
\hline No & 34 & 28 \\
\hline Yes & 85 & 71 \\
\hline Total & 120 & 100 \\
\hline \multicolumn{2}{|r|}{ Source: Primary Data }
\end{tabular}

Interpretation: The above table VII represent that the decision making of the working women where $71 \%$ of the investors has their own decision making, 28\% doesn't take the investment decision where as $1 \%$ of the respondent prefer to take the investment decision from the family. The 
above-mentioned table represent that with financial independence most of the women have increased their knowledge and increased their awareness levels about various investment avenues and have taken their own investment decision that is $71 \%$ of the respondent take their own investment decision. But still there are a big percentage of $28 \%$ women who have not been able to take independent decisions and rely on others for their own investment decisions.

\section{FINDINGS OF THE STUDY}

From this study it is understood that every working woman as an investor has their own kind investment avenues and their preference.

1. From the study it has found that most of the women investors belongs to the age less than 35 years as they possess a good financial knowledge in terms of investment.

2. It is clearly stated that most of the women are comfortable with traditional investment such as LIC, Post Office Scheme and Secured Deposits.

3. As the study shows that the respondents are least interested in investing in stock and debentures or any other commodity market.

4. It is also shown that as the study is for the women, they have $95 \%$ of tendency of investing in Bullion.

5. It is found as major drawback that women are least interested in investing in Art \& Antique as it is highly expensive as per the study the income level of most respondents are between 1 Lakh to 2 Lakh.

6. It is found that the respondents are willing to have medium term (period) of investment.

7. This study found that the respondents prefer to have fixed income securities and also low risk securities mostly.

8. It is found that most of the working women depends on internet resources to invest rather than having proper financial planner.

9. It is found that the respondents are aware of the interest on home loan which is exclusive for women at certain concession.

\section{SUGGESTIONS}

From the study it is observed that most of the working women make their own investment decision in various investment avenues. Yet, majority of them prefer to invest in traditional sources due the "safe saving" mindset.

1. It is observed that the investment pattern of the working women has to be changed. They have to move from a "safe and secure" (risk averse) mentality to an open mindset such as investing in high-risk securities (investment avenues such as hedge, swap, stock and other commodities) as there is higher return available for the future.

2. It is suggested that most of the women have their own decision pattern but no experience in investment. There is a need to popularize investor education programs and to offer continuous training to investors to educate them about newer avenues like cryptocurrency.

3. Investors have incorrect perceptions of some investment avenues due to untrue or fake news, being misled by someone else, and a lack of investment knowledge. As a result, investors form an incorrect opinion or perception of the investment. Eg. Cryptocurrency.

4. It is advised that the investors who aim at a high return for the long-term growth should take a help from professionals such as Financial Planner, Portfolio Manager etc., as they help wisely to invest in the best avenues.

5. From this study it is observed that most of the working women look for high return but not ready to take the risk.

6. It is advised that there should be a separate channel for the investment for the women investors in high-risk securities. Therefore, the women with low income are not considering any of these they just want to clear with their short-term goals.

\section{CONCLUSION}

The above finding clearly indicates that the Women have invested a very small percentage of their income because many women do not have a thorough understanding of all investment avenues and do not want to take risks. A large proportion of women is unable to make independent decisions and must rely on others to make their own investment decisions. The majority of women have not planned for their finances or other investment opportunities and have invested as opportunities have presented themselves. The majority of women believe that liquidity is the most important factor to consider when making investment decisions. Most women have a basic understanding of investing, which is a positive trend that will encourage more women to participate in investing. Most women cannot take risk and thus cannot wait for improvement because they are not high-risk takers with a decrease in portfolio value. Most women have invested in low-risk investments because they are low risk takers. Most women make decisions based on the advice of family members because they require guidance from experienced individuals. Most women have financial goals of generating assets that grow in tandem with the generation of income. It can be concluded that, in general, women are conservative investors who believe that protecting what they have is of the utmost importance.

\section{REFERENCES}

[1] Ali, M. A. (2013). Women and Employment. Institutions Matter: State of Women in Bangladesh.

[2] G, J. V. (2017). A Study on the Perception of Investment Pattern among Urban Working Women with Reference to Coimbatore City. International Journal of Engineering Science and Computing, 7(2).

[3] Getzie, W. A. (2008). Investment Pattern of Professionals - An Empirical Study in Aruppukottai. Madurai Kamaraj University, Madurai.

[4] Jayalakshmi, S. A. (2011, Oct-Dec). Investors Awareness and Preferences. 22(3), 16-18. 
[5] Jhansi Rani Boda, \& Sunitha, G. (n.d.). "nvestor's psychology in investment decision making: A behavioral finance approach, International Journal of Pure and Applied Mathematics, 119(7).

[6] K., P. V. (2013). A Study on Preferred Investment Avenues among Salaried Peoples with Reference to Namakkal Taluk, Tamil Nadu, India. International Conference on Business, Economics, and Accounting.

[7] Kumari, V. K. (2018). Impact of Savings and Investment Behaviour of Working Women in Chennai City. Eurasian Journal of Analytical Chemistry, 13.

[8] Lourrine, A. N. (2017). Factors Affecting the Preference of Investments Among Women- A Study Based on Cochin and Coimbatore. University of Nairobi, 6(1). Retrieved from https://doi.org/10.1007/s00132-012-1917-8

[9] Lubna Ansari, S. M. (2013). Factors Affecting Investing Behaviors Among Young Professionals, International Journal of Technical Research and Applications, 1, (2320-8163).

[10] Rangarajan, R. (2013). Factors Influencing Women Investors in Capital Market - A Study with reference to Chennai City. SMART
Journal of Business Management Studies, 5,

[11] Rao, b. R. (2017, March). A study on investment pattern and Behavior of women employed in private companies in Bangalore. Indian Journal of Applied Research, 7(3).

[12] S. Vasantha, S. A. (2018). Savings and Investment Pattern of Rural Households in Coimbatore District. World Wide Journal of Multidisciplinary Research and Development, 4(1).

[13] Sah, V. P. (2017, December). A Study on Investment Behavioural Patterns of Women Investors. CVR Journal of Science and Technology, 13.

[14] Anagol Malati. (1992). Role of Self-Regulatory Organization in Mutual Fund Industry in India, Chartered Financial Analyst, 7(1), 11.

[15] Anand, S. and Murugaiah, V. (2007). Analysis of components of investment performance - An empirical study of Mutual funds in India. Retrieved from http://www.ssrn.com.

[16] Anjan Chakrabarty and Harsh Rungta. (2000). Mutual Funds Industry in India: An in-depth look into the problems of credibility, Risk and Brand. The ICFAI Journal of Applied Finance, 6(2), 27-45. 